\title{
Is Sexual Conflict an "Engine of Speciation"?
}

\author{
Sergey Gavrilets \\ Department of Ecology and Evolutionary Biology, Department of Mathematics, National Institute \\ for Mathematical and Biological Synthesis, University of Tennessee, Knoxville, Tennessee 37996 \\ Correspondence: gavrila@tiem.utk.edu
}

At the end of the last century, sexual conflict was identified as a powerful engine of speciation, potentially even more important than ecological selection. Earlier work that followed-experimental, comparative, and mathematical—provided strong initial support for this assertion. However, as the field matures, both the power of sexual conflict and constraints on the evolution of reproductive isolation as driven by sexual conflict are becoming better understood. From theoretical studies, we now know that speciation is only one of several possible evolutionary outcomes of sexual conflict. In line with these predictions, both experimental evolution studies and comparative analyses of fertilization proteins and of species richness show that sexual conflict leads to, or is associated with, reproductive isolation and speciation in some cases but not in others. Increased genetic variation (especially in females) without reproductive isolation is an underappreciated consequence of sexually antagonistic selection.

$\mathrm{B}_{\mathrm{f}}^{\mathrm{y}}$ the end of 1990s, studies of sexual conflict and sexually antagonistic coevolution moved to the forefront of experimental and theoretical research in evolutionary biology (Rice and Holland 1997; Holland and Rice 1998; Rice 1998). Although the potential evolutionary importance of sexual conflict was anticipated and articulated from a theoretical point of view by Geoff Parker 20 years earlier (Parker 1979), the explosive interest in this topic was a result of groundbreaking experimental work with Drosophila melanogaster by Bill Rice (1993, 1996), which directly showed high potential for sexually antagonistic coevolution.

Sexual conflict is a special case of intragenomic conflict (Rice and Holland 1997; Rice 1998; Crespi and Nosil 2013). Sexual conflict occurs if the interests of the sexes with regard to certain aspects of reproduction differ (Parker 1979; Arnqvist and Rowe 2005). Ultimately, sexual conflict arises because of the differences in the roles played by the sexes in the process of reproduction, which in turn lead to the differences between the sexes in the costs and benefits of mating and reproduction (Bateman 1948; Trivers 1972; Parker 1979). Sexual conflict can occur over mating rate (Rice and Holland 1997; Holland and Rice 1998; Rice 1998), offspring size (Haig 2000), parental care (Smith and Härdling 2000; Barta et al. 2002), the use of sperm (Ball and Parker 2003), epigenetic control of development (Rice et al. 2012), etc.

Sexual conflict can occur through two genetic routes (Chapman and Partridge 1996; Par-

Editors: William R. Rice and Sergey Gavrilets

Additional Perspectives on The Genetics and Biology of Sexual Conflict available at www.cshperspectives.org

Copyright (C) 2014 Cold Spring Harbor Laboratory Press; all rights reserved; doi: 101101/cshperspect.a017723

Cite this article as Cold Spring Harb Perspect Biol 2014;6:a017723 
ker and Partridge 1998). Within-locus conflict occurs when the locus controls a trait expressed in both sexes and the optimum trait values differ between the sexes. As a result, optimizing the trait value in one sex will lead to a fitness reduction in the other sex. Within-locus conflict can be resolved via a number of mechanisms, including the evolution of sex linkage, sex-specific expression of genes, gene duplication, and condition dependence (Bonduriansky and Chenoweth 2009; van Doorn 2009). Between-locus conflict occurs when there are two different (sets of) traits each expressed in one sex only but affecting the fitness of both sexes in opposite directions. In this case, adaptive changes in a trait of one sex cause deleterious fitness consequences for the other sex, which can be negated by the evolution in a trait of the other sex, which in turn will cause deleterious fitness consequences for the first sex. For example, males can evolve adaptations increasing their mating rate, which would be detrimental for females who would then evolve some counteradaptations to decrease the mating rate (Rice 1996).

One particularly exciting idea that has emerged from studies of sexual conflict and sexually antagonistic coevolution is that sexual conflict can be an important "engine of speciation" (Rice 1996, 1998; Howard et al. 1998; Parker and Partridge 1998). In standard modern perspective, speciation is a result of genetic divergence between populations accompanied by the evolution of reproductive isolation (Howard and Berlocher 1998; Schluter 2000; Coyne and Orr 2004; Dieckmann et al. 2004; Gavrilets 2004). Genetic divergence can be driven by a variety of evolutionary factors, including mutation, random genetic drift, and natural, sexual, and social selection. Reproductive isolation can follow from a variety of mechanisms, resulting in incompatibilities (including genetic, developmental, morphological, ecological, and behavioral) of males and females from diverging populations or in a reduced fitness of their offspring. As was argued by Rice (1998), Parker and Partridge (1998), and others (e.g., Howard et al. 1998), sexual conflict can contribute to these processes in a number of ways.
Below, I briefly summarize several, mostly verbal, theories of biological diversification caused by sexual conflict and then move to discussing some of the more concrete mathematical models and empirical data and patterns.

\section{WITHIN-LOCUS CONFLICT AND SPECIATION}

In general, if within-locus conflict is not resolved (e.g., via sex-specific expression of genes), one would expect that observed trait values in both sexes will deviate from their respective optima. Also, there will be genetic correlations between the traits expressed in males and females so that selection on one sex can cause a correlated response in the other. Unresolved within-locus conflict can impede any form of genetic divergence, reduce the mean fitness of populations, and increase their extinction rate (Bonduriansky and Chenoweth 2009). These effects will also hinder speciation. At the same time, genetic correlations between the traits expressed in males and females can simplify evolution across a valley of maladaptation toward a new optimum for one sex if the other sex is under strong directional selection. This effect can promote speciation (Bonduriansky and Chenoweth 2009).

If within-locus conflict is resolved and male and female traits have evolved to their own new optima, additional effects can occur (Parker and Partridge 1998). First, independent evolution of sexual dimorphism or sex-limited traits by sexual conflict in two isolated populations can result in hybrid breakdown and postzygotic reproductive isolation (Michalak and Noor 2003). Second, such evolution can, as a by-product, affect mate choice traits, which would lead to premating isolation when secondary contact is made. Note that these two effects are not specific to sexual conflict and can happen as a result of genetic divergence driven by any evolutionary factor (Coyne and Orr 2004). At the same time, one can argue that sexually antagonistic genes are more likely than other genes to contribute to incompatibilities between species, because they are responsible for a large part of the standing additive genetic variation and are therefore likely 
to diverge between populations in response to divergent selection.

Recently, SP De Lisle and L Rowe (unpubl.) argued that sexual dimorphism evolving to resolve the sexual conflict may represent a key innovation driving, rather than constraining, diversification. This can happen if the newly acquired ability of the sexes to evolve independently allows them to explore novel parts of the morphospace, which would be maladaptive for a sexually monomorphic species.

\section{BETWEEN-LOCUS CONFLICT AND SPECIATION}

The main emphasis of Rice and Holland (1997) and Rice (1998) was between-locus conflict over mating rate and its consequences for the evolution of reproductive isolation between allopatric populations. They argued that direct deleterious effects of high mating rates on female fitness (e.g., Rice 1996; Rice et al. 2005) will continuously select for increased "resistance" of females to mating attempts from males. Increased resistance in females will in turn result in selection for males able to overcome this resistance. As a consequence, sexual conflict over mating rate will drive perpetual and rapid coevolution of male and female traits controlling reproduction. As a by-product of this coevolution, different allopatric populations will diverge in these traits quickly, losing mutual reproductive compatibility and, thus, becoming different species.

\section{REINFORCEMENT AND SEXUAL CONFLICT}

Parker and Partridge (1998) have also offered a new perspective on a classical scenario of speciation with gene flow: reinforcement. The standard line of reasoning (Dobzhansky 1940; Butlin 1987; Howard 1993) is that if two partially diverged populations start hybridizing and hybrids happen to have reduced fitness, then selection will favor evolution of reinforced premating isolating mechanisms, which would result in decreasing the frequency of unfit hybrids. An implicit assumption here is that both males and females will benefit from reinforce- ment. In contrast, Parker and Partridge (1998) argued that although, in general, females are indeed selected to resist such hybridization, males can benefit from it even if offspring has somewhat reduced fitness. As a result, differences in selection acting on females and on males for acceptance of matings in interpopulation encounters can produce a role for sexual conflict in determining whether reinforcement of mating barriers does or does not occur. Parker and Partridge (1998) made three interesting predictions. First, speciation will be more extensive in groups in which females generally win mating conflicts than in those groups in which males usually win. Second, where there is evidence for reinforcement, it will be the females that are responsible for the resulting premating isolation. Third, in those groups in which females tend to win mating conflicts, the genetic variability within species will be less than that in comparable groups in which males tend to win. Some empirical evidence supports these predictions (Parker and Partridge 1998). At the same time, more recent modeling work has shown that in many cases sexual conflict does not have a winner but rather results in an evolutionary compromise between the sexes (see below). This might limit the generality of the above predictions.

\section{ECOLOGICAL CO-OPTATION}

Bonduriansky (2011) has recently suggested that sexual conflict (and more generally sexual selection) can play an important role in the evolution and diversification of ecological traits and strategies through the co-optation of sexual traits for viability-related functions. He identifies three mechanisms through which this can happen. First, sexual conflict can displace populations from their local ecological optima. Second, sexual traits can serve as a preadaptation for novel ecological functions. For example, sexual selection in an insect species can favor elongated legs in males for grasping females. Longer legs in males can then open a possibility to invade a new ecological niche, such as foraging on wet surfaces. Third, traits that were sex-limited ancestrally (e.g., horns in beetles) can transfer 
S. Gavrilets

between the sexes. A fourth mechanism modeled by van Doorn et al. (2009) is when sexual traits serve as a signal of ecological performance, allowing females to resist mating with a nonlocal male, reducing gene flow between locally adapted populations. Each of these four mechanisms allows populations to explore broader areas of phenotypic space leading to an increase in overall phenotypic diversification and potentially to the emergence of new species.

\section{MODELING CONSEQUENCES OF SEXUAL CONFLICT FOR DIVERSIFICATION}

There are three general approaches that have been used for modeling evolutionary consequences of sexual conflict: classical population genetic models of within-locus conflict, gametheoretic models, and dynamic models of between-locus conflict.

\section{Population Genetic Models of Within-Locus Conflict}

The very first models of within-locus conflict were built by Owen (1953), Bodmer (1965), Karlin (1972), and Kidwell et al. (1977), who studied one-locus two-allele models of a diploid population subject to sex-differential selection. In their models, fitnesses assigned to three different genotypes—say, AA, Aa, and aa-were different for males and females. These models can be viewed as describing the conflict over traits controlling viability or fertility. The results of mathematical analyses show that depending on the strength of selection, the population can evolve to an equilibrium that is optimal for one sex only or an equilibrium describing an evolutionary compromise between the sexes. The models also show that multiple equilibria can be stable simultaneously so that the evolutionary outcome will strongly depend on initial conditions (Owen 1953; Bodmer 1965). A general conclusion from the population genetic models of within-locus conflict is that the conditions for the maintenance of polymorphism at autosomal sexually antagonistic loci are quite strict, much more so than the conditions for the maintenance of sex-linked polymorphism. In some situations, the population will not settle to an equilibrium but rather will instead cycle (Gavrilets 1998). More recently, these models were adopted for describing some enigmatic human traits, such as homosexuality (Gavrilets and Rice 2006; Ciani et al. 2008; Rice et al. 2012), and extended to include more loci (Connallon and Clark 2010) and additional evolutionary factors, such as random genetic drift (Connallon and Clark 2012).

\section{Game-Theoretic Models}

Parker (1979) coined the term sexual conflict in his theoretical study of the possibility of a conflict over mating decision and its possible resolutions. Parker was building on an earlier idea of the "battle-of-the-sexes" game about the costs of raising offspring, which was introduced and studied by Dawkins (1976). Following Parker's groundbreaking work, most earlier modeling studies of sexual conflict used game-theoretical methods to show its existence, provide measures of its intensity, and identify conditions under which alleles or behaviors causing sexual conflict could invade the population (e.g., Jormalainen et al. 1994; Parker and Partridge 1998; Härdling et al. 1999, 2001; Mylius 1999; Alonzo and Warner 2000; Smith and Härdling 2000; Reuter and Keller 2001; Barta et al. 2002; Andres and Morrow 2003; Ball and Parker 2003). Parker and Partridge (1998) applied this approach to the problem of reinforcement as discussed above.

\section{Evolutionary Dynamics of Between-Locus Conflict}

A major component of modeling the evolutionary consequences of between-locus conflict has been done for a conflict over mating rate, an issue playing a prominent role in Rice's arguments. To illustrate the logic of the theoretical approaches used, assume that mating and/or fertilization are controlled by the interaction of trait $x$ in females and trait $y$ in males. Let us specify a mating compatibility function $\psi(x, y)$ giving a probability of mating (or fertilization) between a female with trait $x$ and a male with 
trait $y$. Function $\psi$ is analogous to the preference function in models of sexual selection (Lande 1981; Gavrilets 2004). Let $x$ and $y$ be the average female and male traits in the population. Then function $P=\psi(x, y)$ can be viewed as a measure of how well a female with trait $x$ is compatible with the typical males in her population. Analogously, function $Q=\psi(x, y)$ can be viewed as a measure of how well a male with trait $y$ is compatible with the typical females in his population. With everything else held the same, $P$ and $Q$ can also be viewed as measures of mating rates for the two sexes. For males, reproductive success is expected to increase monotonically with $Q$ (e.g., linearly as in Fig. 1A). In contrast, for females, mating rates that are too high can be detrimental, meaning female fitness is maximized at an intermediate value of $P_{\text {opt }}$ as in Figure 1B.

Turning to the function of mating compatibility $\psi(x, y)$, there are two major types capturing different biological mechanisms. First, if mating requires complementarity or matching of the male and female traits, then $\psi$ can be modeled as a unimodal function of the difference $y-x$ (Fig. 1C). In this case, females can achieve an optimum mating rate by evolving their trait $x$ to be larger or smaller than the male trait $y$. Second, if mating is more of a contest between male "offense" and female "defense" traits in which extreme "offense" trait values would always be beneficial for males, then $\psi$ can be modeled as an increasing function of the difference $y-x$ (Fig. 1D). In this case, females can achieve an optimum mating rate by evolving stronger and stronger "defense" trait $x$.

Rice's original discussion of the evolutionary consequences of sexual conflict over mating has mostly concentrated on the regime of perpetual coevolutionary chase between the sexes (Rice 1996, 1998; Holland and Rice 1998). Mathematical models have confirmed that such a chase between the average traits $x$ and $y$ in the population is indeed possible. However, mathematical models also show that coevolutionary chase is but one of several possibilities. Overall, there are at least six different dynamic regimes observed in models of between-locus
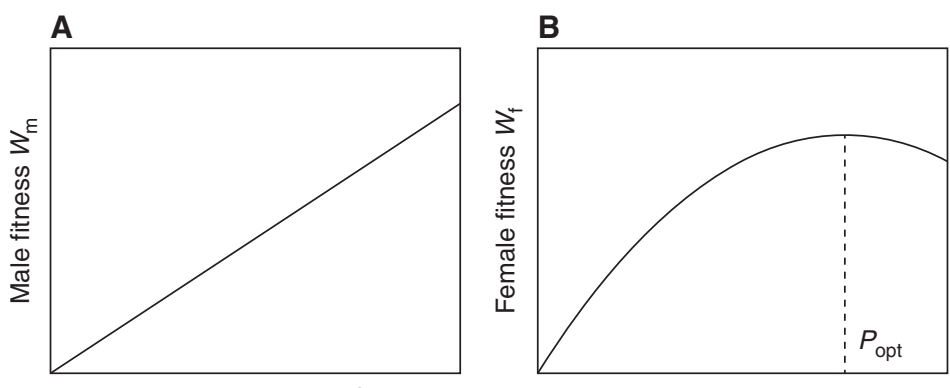

Male mating rate $Q$

Female mating rate $P$
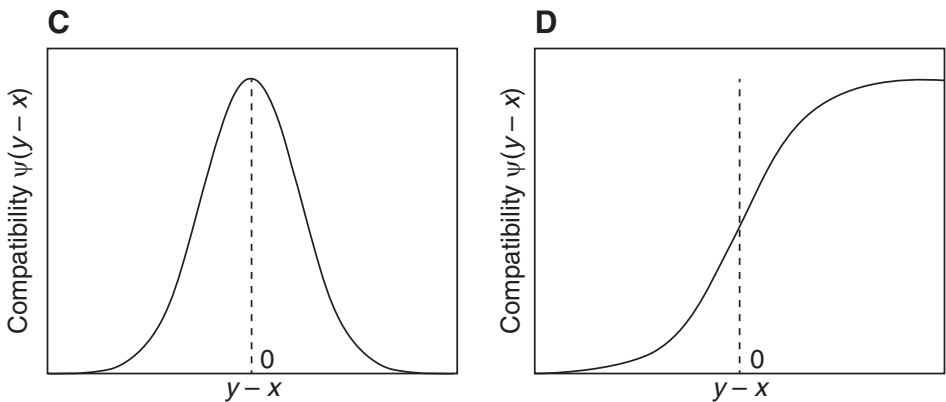

Figure 1. Modeling between-locus sexual conflict. $(A)$ Male fitness increases with mating rate. $(B)$ For females, there is an optimum mating rate $P_{\text {opt }}(C)$ Successful mating requires complementarity of male and female traits $(y=x) .(D)$ Successful mating requires male "offense" trait $y$ to overcome female "defense" trait $x$. 
S. Gavrilets

sexual conflict: continuous coevolutionary chase between the sexes (Gavrilets 2000; Gavrilets et al. 2001; Gavrilets and Waxman 2002; Rowe et al. 2003; Gavrilets and Hayashi 2006), evolution toward an equilibrium (Kondoh and Higashi 2000; Gavrilets et al. 2001; Kimura and Ihara 2009), evolution toward a line of equilibria with subsequent random drift along this line (Gavrilets 2000; Gavrilets and Hayashi 2005; Hayashi et al. 2007), cyclic evolution (Gavrilets et al. 2001; Haygood 2004), Buridan's ass regime involving extensive diversification in female alleles without comparable diversification in male alleles (Frank 2000; Gavrilets and Waxman 2002; Gavrilets and Hayashi 2005; Hayashi et al. 2007), and extensive diversification in both male and female alleles (Frank 2000; Gavrilets and Hayashi 2005; Härdling and Bergsten 2006; Hayashi et al. 2007; Härdling and Karlsson 2009), including a possibility of sympatric speciation (Gavrilets and Waxman 2002; Hayashi et al. 2007). Mathematical models (Gavrilets and Hayashi 2005; Hayashi et al. 2007) also show that different dynamic regimes can be observed with the same set of parameter values but under different initial conditions; populations can switch from one regime to another as a result of stochastic perturbations owing to, say, random genetic drift; and different sets of loci controlling mating and fertilization in the same population can follow different dynamic regimes. In short, the behavior of models of sexual conflict is extremely varied and complex (Rowe et al. 2003; Gavrilets and Hayashi 2005). Frequency-dependent selection is well recognized for its ability to result in complex evolutionary dynamics (Altenberg 1991; Gavrilets and Hastings 1995). In the case of between-locus sexual conflict, selection is not only frequency dependent, but also sex differential, whereas between-sexes interactions include both conflict and cooperation. Therefore, the complexity of resulting evolutionary dynamics is probably not that unexpected.

What does all this tell us about the possibility of speciation by sexual conflict? Out of the six regimes listed above, two regimes are the most intriguing in this regard. The first regime (i.e., continuous coevolutionary chase between the sexes) will eventually lead to allopatric speciation as a by-product if diverging populations keep evolving in different directions and/or at different rates. The sixth regime (i.e., extensive diversification in both male and female alleles) can lead to sympatric speciation if the diversification is in the form of distinct cluster formation. The four other regimes will typically lead to increased genetic variation in the population but not to speciation per se.

The question of which outcome-speciation or increased genetic variation without speciation-is more general can hardly be answered. The answer will depend on a number of specific biological factors and details, which will most likely vary between different organisms or populations. Mathematical models, however, do allow us to get a better understanding of the effects of these factors. However, models often make predictions in terms of more abstract model parameters; the challenge, then, is to link them with empirical data.

Lessells (2006) offered an insightful analysis of evolutionary outcomes of sexual conflict in terms of three sets of variables: (1) benefits of male "offense" and female "defense"; (2) costs of "offense" and "defense"; and (3) feasibility of "offense." Obviously, continuous coevolutionary chase is only possible if it is not constrained by natural selection on the alleles and traits underlying reproduction (so that the costs of "offense" and "defense" are low, whereas feasibility of "offense" is high). Parker and Partridge (1998) argued that the cost of resistance for females can be lower than those for males of imposing a mating. At the same time, the opportunity costs for males are expected to be low (Lessells 2006). If mating requires matching or complementarity of male and female traits (as assumed in Fig. 1C), then male "offense" and female "defense" are more likely to be realized without a systematic change in the underlying traits. In this case, costs may be lower and the opportunity for substantial divergence and speciation higher. If mating is more of a contest (as assumed in Fig. 1C), in which success requires a systematic increase in the efficiency of underlying mating traits, then increasing costs are more likely. These costs will prevent perpetual evolu- 
tionary change and constrain speciation (Lessells 2006).

However, the absence of constraints does not guarantee that coevolutionary chase will be observed. Modeling shows (Hayashi et al. 2007) that it is also necessary that the population has relatively low levels of genetic variation and that the plausibility of coevolutionary chase is strongly affected by the genetics of between-sexes interactions. In particular, coevolutionary chase is more plausible if these interactions are mediated by additive quantitative characters than if multiple dominant alleles are involved. In other words, genetic details are also important.

The absence of clear-cut conclusions can make a disappointed reader question the utility of mathematical modeling sexual conflict, but such modeling did clarify the logic of verbal arguments, make them more precise, identify the most important parameters and relevant timescales, and stimulate novel empirical work. Moreover, mathematical modeling has resulted in several novel conclusions that were not included in earlier discussions of sexual conflict. One example of this is that females can reduce the burden of sexual conflict by diversifying genetically rather than by "running" away from males (Buridan's ass regime) (Gavrilets and Waxman 2002). Genetic variation in females is maintained because sexual conflict generates negative-frequency-dependent selection (i.e., rare female types do better) because the males will tend to optimize their mating rate with whichever female type is most abundant. This situation stands in contrast to models of sexual selection in which the interests of males and females typically align. The diversification in females can be answered by diversification in males, potentially leading to sympatric speciation. The extent of diversification and whether or not it results in the formation of distinct genetic clusters within the population depend on a number of different factors including the strength of sexual conflict, the strength of natural selection, the population size, and the genetics of the traits involved. Another conclusion is that genetic variation in female alleles/traits can be larger than that in males. The level of genetic variation in both sexes is also predicted to increase with the strength of sexual conflict. Yet another prediction is that the evolved mating rate is often intermediate between the one optimum for females and the one optimum for males. Therefore, in this case, sexual conflict is not won by one sex but rather there is a (dynamic or static) evolutionary compromise between the sexes.

At the same time, the existing models of sexual conflict are far from being comprehensive (Gavrilets and Hayashi 2005; Lessells 2006). For example, competition between males is not explicitly modeled, spatial models are still lacking, between-sexes interactions are modeled in a rather abstract way despite there being much more currently known about the underlying mechanisms of, say, sperm-egg interactions, the ecological divergence required for coexistence of different species is not considered, and only a single study (Gavrilets and Hayashi 2006) has attempted to model three-way interactions (between male offense, male defense, and female defense) important in Rice's arguments.

\section{EMPIRICAL PATTERNS}

Experimental evidence both that high mating rates can be quite detrimental to female fitness and that sexual conflict can drive rapid genetic changes in experimental populations are quite solid (e.g., Rice 1996; Holland and Rice 1999; Pitnick et al. 2001a,b; Rice et al. 2005). How easily these genetic changes result in reproductive isolation and speciation is much less clearcut. There are three sets of relevant empirical approaches: experimental evolution, analyses of fertilization traits and proteins, and comparative studies of species richness.

\section{Experimental Evolution of Reproductive Isolation}

The first study of the evolution of reproductive isolation by sexual conflict under laboratory conditions was that by Martin and Hosken (2003) using populations of the dung fly Sepsis cynipsea. In this species, males' armored geni- 
S. Gavrilets

talia often injure females internally during copula. Injuries are visible as sclerotized scars in the female ovipositor, and their occurrence increases with mating frequency. Presumably owing to these injuries, mated females show higher mortality (Blanckenhorn et al. 2002). Females typically attempt to dislodge mounted males by harassing them with vigorous shaking. Martin and Hosken (2003) manipulated population densities and then measured copulation success between a male and a female chosen from populations subject to different or the same treatments for 35 generations. They showed that copulation frequency was greater in pairings within conflict populations than those between populations in which conflict was removed, and this effect was stronger in high-density than in low-density populations. Evidence of female (but not male) resistance to flies from other conflict populations implies that sexual conflict drives divergence (Martin and Hosken 2003; Hosken et al. 2009).

However, similar subsequent experiments have largely failed to provide evidence for the evolution of reproductive isolation. These include experiments with D. melanogaster (Wigby and Chapman 2006, but see Ghosh and Joshi 2012), Drosophila pseudoobscura (Bacigalupe et al. 2007), bruchid beetle populations Callosobruchus maculatus (Gay et al. 2009), water strider Gerris gillettei (Gagnon and Turgeon 2011), and the bulb mite Rhizoglyphus robini (Plesnar-Bielak et al. 2013).

Several factors can explain the negative results: The experiments may be too short to cause a noticeable effect, the populations could have evolved in a similar direction at a similar rate, or the dynamics imposed by the experimental conditions were different from the "coevolutionary chase."

\section{Fertilization Traits and Proteins}

A very large amount of experimental data coming from studies of sperm or pollen competition between closely related species (e.g., Arnold et al. 1993; Wade et al. 1994; Rieseberg 1995; Howard et al. 1998; Howard 1999), as well as from molecular studies of fertilization proteins (e.g., Aguade et al. 1992; Lee and Vacquire 1992; Vacquier and Lee 1993; Metz and Palumbi 1996; Palumbi 1998; Howard 1999; Swanson and Vacquier 2002a,b; Galindo et al. 2003; Landry et al. 2003; Swanson et al. 2003), indicates that in many diverging taxa, traits and proteins related to fertilization evolve extremely rapidly. At least in the case of marine organisms, there now appears to be a consensus that these data can be explained in large part by selection for avoidance of polyspermy (Levitan et al. 2007; Palumbi 2009; Lessios 2011; Vacquier and Swanson 2011). Sperm is under strong selection for increased efficiency in fertilizing eggs, but if more than one sperm penetrates the egg, the resulting zygote in usually inviable. Polyspermy thus represents an important example of sexual conflict over mating rate (Howard et al. 1998). Avariety of mathematical models of the effects of polyspermy all converge on the prediction of a rapid coevolutionary chase between the traits of sperm and eggs with sperm evolving to increase their efficiency and eggs evolving molecular "defense" against sperm (Frank 2000; Gavrilets 2000; Gavrilets and Waxman 2002; Haygood 2004; Tomaiuolo and Levitan 2006; Hayashi et al. 2007). Sperm-egg interactions are more likely to require complementarity at the gene-product level than contest (Fig.1C,D) (Rice 1998; Lessells 2006), which, as discussed above, makes continuous "evolutionary chase" more plausible.

Mathematical models of sexual conflict also provide explanations for certain empirical patterns that were previously rather puzzling. These include apparent deceleration in the evolution of sperm lysin genes in abalone (Yang et al. 2000) and complex genetic clustering in sperm protein bindin in sea urchins (Palumbi 1999), in sperm lysin genes in abalone (Swanson et al. 2001), and in sea urchin gamete recognition genes (Vacquier and Moy 1997).

The data also indicate a potential role for reinforcement, because, in some cases, the rate of evolution and the extent of polymorphism correlate with the number of sympatric species (Vacquier and Swanson 2011). However, rapid evolution of fertilization proteins is not universal. For example, for some allopatric species of 
sea urchins that diverged more than 4-9 million years, there is no evidence of positive selection in bindin alleles that evolve very rapidly in other species (Vacquier and Swanson 2011).

Selection for increased female resistance to mating can also potentially explain rapid evolution of genitalia, which has been observed in many organisms (Eberhard 1985). One can then predict that the differences in genitalic form among congeneric species in which females are protected from male harassment should be less common than differences among congeneric species in which females are vulnerable to harassment by males. This prediction, however, has failed for a large sample of insects and spiders (Eberhard 2004). At the same time, recent comparative studies of water strider populations provide strong evidence for a persistent coevolutionary chase between male and female sexual traits affecting reproductive isolation (Ronn et al. 2007; Perry and Rowe 2012).

\section{Species Richness}

The results of comparative studies of the effects of sexual conflict and sexual selection on species richness are equivocal (Parker 2006). Some data show positive correlation between species richness (i.e., the number of species in a clade) and some measures that can be interpreted as proxies for a potential sexual conflict. Arnqvist et al. (2000) were the first to use comparative data to analyze the effects of sexual conflict on largescale diversification. These investigators contrasted pairs of related groups of insect species differing in the opportunity for sexual conflict. The latter was characterized by the number of matings per female. Arnqvist et al. (2000) showed that groups in which females mate with many males exhibited speciation rates four times as high as in related groups in which females mate only once. In the hoverflies, higher levels of sexual selection are associated with higher species richness (Katzourakis et al. 2001). Barraclough et al. (1995) showed that species richness correlates with the proportion of sexually dichromatic species within taxa of passerine birds. In birds, taxa with promiscuous mating systems tend to be more species-rich than their nonpromiscuous sister taxa (Mitra et al. 1996). Data on Amphibia show that sexual size dimorphism is associated with increased species richness, diversification rate, and reduced extinction risk (Lisle and Rowe 2014). However, the prediction about the positive relationship between the number of species in a clade and a potential for sexual conflict does not hold in some mammals, butterflies, spiders (Gage et al. 2002), birds (Morrow et al. 2003), and fish (Ritchie et al. 2005). There are some issues with the interpretation of the results of comparative studies attributed to the difficulties for controlling for phylogenetic effects, sexual selection, and extinction (Panhuis et al. 2001; Coyne and Orr 2004).

\section{Female Polymorphism}

As was emphasized above, mathematical theory predicts that sexual conflict can lead to speciation only under specific conditions. If these conditions are not satisfied, populations are expected to diversify. In particular, an interesting prediction emerging from theoretical studies is that females can sometimes get the upper hand in sexual conflict and decrease male harassment by diversifying genetically (Franke et al. 2002; Gavrilets and Waxman 2002; Gavrilets and Hayashi 2005; Härdling and Bergsten 2006; Hayashi et al. 2007). Overall, female sexual polymorphisms appear to be overlooked in the past as most studies of sexual selection focused on male-male competition (Svensson et al. 2009). However, by now there are a number of well-studied cases in which female sexual polymorphism has been shown and linked to sexual conflict. These include higher genetic variation in female reproductive traits in carabid beetles (Sota et al. 2000) and apparent polymorphisms in female genitalia in a spider species (Huber and González, 2001), an African bat bug (Reinhardt et al. 2007), the guppy (Evans et al. 2013), black scavenger flies (Puniamoorthy et al. 2010), butterflies (Cook et al. 1994), diving beetles (Härdling and Bergsten 2006), and damselflies (Van Gossum et al. 2008; Svensson et al. 2009). A study in damselflies explicitly looked at frequency- and density-dependent fecundity pat- 
S. Gavrilets

terns (Iserbyt et al. 2013). The results are consistent with the hypothesis that the polymorphism is driven by a conflict between sexes over mating rate, with costly male sexual harassment driving negative-frequency-dependent selection on morph fecundity.

\section{CONCLUDING REMARKS}

Earlier experimental, comparative, and mathematical work has provided strong support for the idea that sexually antagonistic selection is a powerful engine of speciation. However, we now much better understand the constraints and limitations on the evolution of reproductive isolation as driven by sexual conflict. Modeling work shows that speciation is only one of several possible evolutionary outcomes of sexual conflict and can occur only under specific conditions. In a similar vein, both experimental evolution studies and comparative analyses of fertilization proteins and of species richness show that sexual conflict leads to, or is associated with, reproductive isolation and speciation in some cases but not in others. Sexual conflict is an engine of speciation. But as with other engines of speciation and diversification-ecological selection, sexual selection, and accumulation of incompatibilities between diverging lineages by mutation and drift-it is most efficient when operating under optimal conditions and can stall otherwise.

\section{ACKNOWLEDGMENTS}

I thank W. R. Rice, K. Rooker, L. Rowe, and G. S. van Doorn for comments and suggestions. This work is supported by the National Institute for Mathematical and Biological Synthesis through National Science Foundation Award \#EF-0830858, with additional support from The University of Tennessee, Knoxville.

\section{REFERENCES}

Aguade M, Miyashita N, Langley CH. 1992. Polymorphism and divergence in the Mst26A male accessory gland gene region in Drosophila. Genetics 132: 755-770.
Alonzo SH, Warner RR. 2000. Dynamic games and field experiments examining intra- and intersexual conflict: Explaining counterintuitive mating behavior in a Mediterranean wrasse, Symphodus ocellatus. Behav Ecol 11: $56-70$.

Altenberg L. 1991. Chaos from linear frequency-dependent selection. Am Nat 138: 51-68.

Andres JA, Morrow EH. 2003. The origin of interlocus sexual conflict: Is sex-linkage important? JEvol Biol 16:219-223.

Arnold ML, Hamrick JL, Bennett BD. 1993. Interspecific pollen competition and reproductive isolation in Iris. J Hered 84: 13-16.

Arnqvist G, Rowe L. 2005. Sexual conflict. Princeton University Press, Princeton, NJ.

Arnqvist G, Edvardsson M, Friberg U, Nilsson T. 2000. Sexual conflict promotes speciation in insects. Proc Natl Acad Sci 97: 10460-10464.

Bacigalupe LD, Crudgington HS, Hunter F, Moore AJ, Snook RR. 2007. Sexual conflict does not drive reproductive isolation in experimental populations of Drosophila pseudoobscura. J Evol Biol 20: 1763-1771.

Ball MA, Parker GA. 2003. Sperm competition games: Sperm selection by females. J Theor Biol 224: 27-42.

Barraclough TG, Harvey PH, Nee S. 1995. Sexual selection and taxonomic diversity in passerine birds. Proc Biol Sci 259: 211-215.

Barta ZN, Houston AI, McNamara JM, Szekely T. 2002. Sexual conflict about parental care: The role of reserves. Am Nat 159: 687-705.

Bateman AJ. 1948. Intrasexual selection in Drosophila. Heredity 2: $349-368$.

Blanckenhorn W, Hosken D, Martin O, Reim C, Teuschl Y, Ward P. 2002. The costs of copulating in the dung fly Sepsis cynipsea. Behav Ecol 13: 353-358.

Bodmer WF. 1965. Differential fertility in population genetics models. Genetics 51: 411-424.

Bonduriansky R. 2011. Sexual selection and conflict as engines of ecological diversification. Am Nat 178: 729-745.

Bonduriansky R, Chenoweth SF. 2009. Intralocus sexual conflict. Trends Ecol Evol 24: 280-288.

Butlin R. 1987. Speciation by reinforcement. Trends Ecol Evol 2: 8-13.

Chapman T, Partridge L. 1996. Female fitness in Drosophila melanogaster: An interaction between the effect of nutrition and of encounter rate with males. Proc Biol Sci 263: $755-759$.

Ciani AC, Cermelli P, Zanzotto G. 2008. Sexually antagonistic selection in human male homosexuality. PLoS ONE 3: e2282.

Connallon T, Clark AG. 2010. Sex linkage, sex-specific selection, and the role of recombination in the evolution of sexually dimorphic gene expression. Evolution 64: 34173442.

Connallon T, Clark AG. 2012. A general population genetic framework for antagonistic selection that accounts for demography and recurrent mutation. Genetics 190: 1477-1489.

Cook S, Vernon J, Bateson M, Guilford T. 1994. Mate choice in the polymorphic African swallowtail butterfly, Papilio 
dardanus: Male-like females may avoid sexual harassment. Anim Behav 47: 389-397.

Coyne J, Orr HA. 2004. Speciation. Sinauer Associates, Sunderland, MA.

Crespi B, Nosil P. 2013. Conflictual speciation: Species formation via genomic conflict. Trends Ecol Evol 28: 48-57.

Dawkins R. 1976. The selfish gene. Oxford University Press, Oxford.

Dieckmann U, Doebeli M, Metz JAJ, Tautz D. 2004. Adaptive speciation. Cambridge University Press, Cambridge.

Dobzhansky TG. 1940. Speciation as a stage in evolutionary divergence. Am Nat 74: 312-321.

Eberhard WG. 1985. Sexual selection and animal genitalia. Harvard University Press, Cambridge, MA.

Eberhard WG. 2004. Male-female conflict and genitalia: Failure to confirm predictions in insect and spiders. Biol Rev Camb Philos Soc 79: 121-186.

Evans JP, van Lieshout E, Gasparini C. 2013. Quantitative genetic insights into the coevolutionary dynamics of male and female genitalia. Proc Biol Sci 280: 20130749.

Frank SA. 2000. Sperm competition and female avoidance of polyspermy mediated by sperm-egg biochemistry. Evol Ecol Res 2: 613-625.

Franke ES, Styan CA, Babcock R. 2002. Sexual conflict and polyspermy under sperm-limited conditions: In situ evidence from field simulations with the free-spawning marine echinoid Evechinus chloroticus. Am Nat 160: 485496.

Gage MJG, Parker GA, Nylin S, Wiklund C. 2002. Sexua selection and speciation in mammals, butterflies and spiders. Proc Biol Sci 269: 2309-2316.

Gagnon MC, Turgeon J. 2011. Sexual conflict in Gerris gillettei (Insecta: Hemiptera): Intraspecific intersexual correlated morphology and experimental assessment of behaviour and fitness. J Evol Biol 24: 1505-1516.

Galindo BE, Vacquier VD, Swanson WJ. 2003. Positive selection in the egg receptor for abalone sperm lysin. Proc Natl Acad Sci 100: 4639-4643.

Gavrilets S. 1998. One-locus two-allele models with maternal (parental) selection. Genetics 149: 1147-1152.

Gavrilets S. 2000. Rapid evolution of reproductive isolation driven by sexual conflict. Nature 403: 886-889.

Gavrilets S. 2004. Fitness landscapes and the origin of species. Princeton University Press, Princeton, NJ.

Gavrilets S, Hastings A. 1995. Intermittency and transient chaos from simple frequency-dependent selection. Proc Biol Sci 261: 233-238.

Gavrilets S, Hayashi TI. 2005. Speciation and sexual conflict. Evol Ecol 19: 167-198.

Gavrilets S, Hayashi TI. 2006. The dynamics of two- and three-way sexual conflicts over mating. Phil Trans $R \operatorname{Soc} B$ 261: $345-354$.

Gavrilets S, Rice WR. 2006. Genetic models of homosexuality: Generating testable predictions. Proc Biol Sci 273: 3031-3038.

Gavrilets S, Waxman D. 2002. Sympatric speciation by sexual conflict. Proc Natl Acad Sci 99: 10533-10538.

Gavrilets S, Arnqvist G, Friberg U. 2001. The evolution of female mate choice by sexual conflict. Proc Biol Sci 268: $531-539$.
Gay L, Eady PE, Vasudev R, Hosken DJ, Tregenza T. 2009 Does reproductive isolation evolve faster in larger populations via sexually antagonistic coevolution? Biol Lett 5: 693-696.

Ghosh SM, Joshi A. 2012. Evolution of reproductive isolation as a by-product of divergent life-history evolution in laboratory populations of Drosophila melanogaster. Ecol Evol 2: 3214-3226.

Haig D. 2000. The kinship theory of genomic imprinting. Annu Rev Ecol Syst 31: 9-32.

Härdling R, Bergsten J. 2006. Nonrandom mating preserves intrasexual polymorphism and stops population differentiation in sexual conflict. Am Nat 167: 401-409.

Härdling R, Karlsson K. 2009. The dynamics of sexually antagonistic coevolution and the complex influences of mating system and genetic correlation. J Theor Biol 260: 276-282.

Härdling R, Jormalainen V, Tuomi J. 1999. Fighting costs stabilize aggressive behavior in intersexual conflicts. Evol Ecol 13: 245-265.

Härdling R, Smith HG, Jormalainen V, Tuomi J. 2001. Resolution of evolutionary conflicts: Costly behaviours enforce the evolution of cost-free competition. Evol Ecol Res 3: 829-844.

Hayashi TI, Vose M, Gavrilets S. 2007. Genetic differentiation by sexual conflict. Evolution 61: 516-529.

Haygood R. 2004. Sexual conflict and protein polymorphism. Evolution 58: 1414-1423.

Holland B, Rice WR. 1998. Chase-away sexual selection: Antagonistic seduction versus resistance. Evolution 52: $1-7$.

Holland B, Rice WR. 1999. Experimental removal of sexual selection reverses intersexual antagonistic coevolution and removes a reproductive load. Proc Natl Acad Sci 96: 5083-5088.

Hosken DJ, Martin OY, Hy S, Chapman T, Hodgson DJ. 2009. Sexual conflict and reproductive isolation in flies. Biol Lett 5: 697-699.

Howard DJ. 1993. Reinforcement: Origin, dynamics, and fate of an evolutionary hypothesis. In Hybrid zones and the evolutionary process (ed. Harrison RG), pp. 46-69. Oxford University Press, New York.

Howard DJ. 1999. Conspecific sperm and pollen precedence and speciation. Annu Rev Ecol Syst 30: 109-132.

Howard DJ, Berlocher SH. 1998. Endless forms: Species and speciation. Oxford University Press, New York.

Howard DJ, Reece M, Gregory PG, Chu J, Cain ML. 1998. The evolution of barriers to fertilization between closely related organisms. In Endless forms: Species and speciation (ed. Howard DJ, Berlocher SH), pp. 279-288. Oxford University Press, New York.

Huber BA, González AP. 2001. Female genital dimorphism in a spider (Araneae: Pholcidae). J Zoology 255: 301-304.

Iserbyt A, Bots J, Van Gossum H, Sherratt TN. 2013. Negative frequency-dependent selection or alternative reproductive tactics: Maintenance of female polymorphism in natural populations. BMC Evol Biol 13.

Jormalainen V, Tuomi J, Yamamura N. 1994. Intersexual conflict over precopula duration in mate guarding Crustacea. Behav Proc 32: 265-283. 
S. Gavrilets

Karlin S. 1972. Some mathematical models of population genetics. Am Math Monthly 79: 699-739.

Katzourakis A, Purvis A, Azmeh S, Rotheray G, Gilbert F. 2001. Macroevolution of hoverflies (Diptera:Syrphidae): The effect of using higher-level taxa in studies of biodiversity, and correlates of species richness. J Evol Biol 14: 219-227.

Kidwell J, Clegg M, Swewart F, Prout T. 1977. Regions of stable equilibria for models of differential selection in 2 sexes under random mating. Genetics 85: 171-183.

Kimura M, Ihara Y. 2009. Replicator-dynamics models of sexual conflict. J Theor Biol 260: 90-97.

Kondoh M, Higashi M. 2000. Reproductive isolation mechanism resulting from resolution of intragenomic conflict. Am Nat 156: 511-518.

Lande R. 1981. Models of speciation by sexual selection on polygenic characters. Proc Natl Acad Sci 78: 3721-3725.

Landry C, Geyer LB, Arakaki Y, Uehara T, Palumbi SR. 2003. Recent speciation in the Indo-West Pacific: Rapid evolution of gamete recognition and sperm morphology in cryptic species of sea urchin. Proc Biol Sci 270: 18391847.

Lee YH, Vacquire VD. 1992. The divergence of species-specific abalone sperm lysins is promoted by positive Darwinian selection. Biol Bull 182: 97-104.

Lessells C. 2006. The evolutionary outcome of sexual conflict. Phil Trans R Soc B 361: 301-317.

Lessios H. 2011. Speciation genes in free-spawning marine invertebrates. Integr Comp Biol 51: 456-465.

Levitan DR, terHorst C, Fogarty N. 2007. The risk of polyspermy in three congeneric sea urchins ad its implications for gametic incompatibility and reproductive isolation. Evolution 61: 2009-2016.

Martin O, Hosken D. 2003. The evolution of reproductive isolation through sexual conflict. Nature 423: 979-982.

Metz E, Palumbi S. 1996. Positive selection and sequence rearrangements generate extensive polymorphism in the gamete recognition protein bindin. Mol Biol Evol 13: 397-406.

Michalak P, Noor M. 2003. Genome-wide patterns of expression in Drosophila pure species and hybrid males. Mol Biol Evol 20: 1070-1076.

Mitra S, Landel H, Pruett-Jones S. 1996. Species richness covaries with mating system in birds. Auk 113: 544-551.

Morrow E, Pitcher TE, Arnqvist G. 2003. No evidence that sexual selection is an "engine of speciation" in birds. Ecol Lett 6: 228-234.

Mylius SD. 1999. What pair formation can do to the battle of the sexes: Towards more realistic game dynamics. J Theor Biol 197: 469-485.

Owen A. 1953. A genetical system admitting of 2 distinct stable equilibria under natural selection. Heredity 7: $97-$ 102.

Palumbi SR. 1998. Species formation and the evolution of gamete recognition loci. In Endless forms: Species and speciation (ed. Howard DJ, Berlocher SH), pp. 271278. Oxford University Press, New York.

Palumbi SR. 1999. All males are not created equal: Fertility differences depend on gamete recognition polymor- phisms in sea urchins. Proc Natl Acad Sci 967: 1263212637.

Palumbi S. 2009. Speciation and the evolution of gamete recognition genes: Pattern and process. Heredity 102: 66-76.

Panhuis TM, Butlin R, Zuk M, Tregenza T. 2001. Sexual selection and speciation. Trends Ecol Evol 16: 364-371.

Parker GA. 1979. Sexual selection and sexual conflict. In Sexual selection and reproductive competition in insects (ed. Blum MS, Blum NA), pp. 123-166. Academic, New York.

Parker GA. 2006. Sexual conflict over mating and fertilization: An overview. Phil Trans R Soc B 361: 235-259.

Parker GA, Partridge L. 1998. Sexual conflict and speciation. Phil Trans R Soc B 353: 261-274.

Perry JC, Rowe L. 2012. Sexual conflict and antagonistic coevolution across water strider populations. Evolution 66: $544-557$.

Pitnick S, Brown WD, Miller GT. 2001a. Evolution of female remating behavior following experimental removal of sexual selection. Proc Biol Sci 268: 557-563.

Pitnick S, Miller GT, Reagan J, Holland B. 2001b. Males' evolutionary responses to experimental removal of sexual selection. Proc Biol Sci 268: 1071-1080.

Plesnar-Bielak A, Skrzynecka AM, Prokop ZM, Kolasa M, Dzialo M, Radwan J. 2013. No evidence for reproductive isolation through sexual conflict in the bulb mite Rhizoglyphus robini. PLoS ONE 8: e74971.

Puniamoorthy N, Kotrba M, Meier R. 2010. Unlocking the "Black box": Internal female genitalia in Sepsidae (Diptera) evolve fast and are species-specific. BMC Evol Biol 10: 275.

Reinhardt K, Harney E, Naylor R, Gorb S, Siva-Jothy MT. 2007. Female-limited polymorphism in the copulatory organ of a traumatically inseminating insect. Am Nat 170: $931-935$.

Reuter M, Keller L. 2001. Sex ratio conflict and worker production in eusocial Hymenotera. Am Nat 158: 166-177.

Rice WR. 1993. Sexually antagonistic genes: Experimental evidence. Science 256: 1436-1439.

Rice WR. 1996. Sexually antagonistic male adaptation triggered by experimental arrest of female evolution. Nature 381: $232-234$.

Rice WR. 1998. Intergenomic conflict, interlocus antagonistic coevolution, and the evolution of reproductive isolation. In Endless forms: Species and speciation (ed. Howard DJ, Berlocher SH), pp. 261-270. Oxford University Press, New York.

Rice WR, Holland B. 1997. The enemies within: Intergenomic conflict, interlocus contest evolution (ICE), and intraspecific Red Queen. Behav Ecol Sociobiol 41: 1-10.

Rice W, Linder J, Friberg U, Lew T, Morrow E, Stewart A. 2005. Inter-locus antagonistic coevolution as an engine of speciation: Assessment with hemiclonal analysis. Proc Natl Acad Sci 102: 6527-6534.

Rice W, Friberg U, Gavrilets S. 2012. Homosexuality as a consequence of epigenetically canalized sexual development. Q Rev Biol 87: 343-346.

Rieseberg LH. 1995. The role of hybridization in evolution: Old wine in new skins. Am J Bot 82: 944-953. 
Ritchie M, Webb S, Graves J, Magurran A, Garcia C. 2005 Patterns of speciation in endemic Mexican Goodeid fish: Sexual conflict or early radiation? J Evol Biol 18: 922-929.

Ronn J, Katvala M, Arnqvist G. 2007. Coevolution between harmful male genitalia and female resistance in seed beetles. Proc Natl Acad Sci 104: 10921-10925.

Rowe L, Cameron E, Day T. 2003. Detecting sexually antagonistic coevolution with population crosses. Proc Biol Sci 270: 2009-2016.

Schluter D. 2000. The ecology of adaptive radiation. Oxford University Press, Oxford.

Smith HG, Härdling R. 2000. Clutch size evolution under sexual conflict enhances the stability of mating systems. Proc Biol Sci 267: 2163-2170.

Sota T, Kusumoto F, Kubota K. 2000. Consequences of hybridization between Ohomopterus insulicola and O. arrowianus (Coleoptera, Carabidae) in a segmented river basin: Parallel formation of hybrid swarms. Biol $J$ Linn Soc 71: 297-313.

Svensson EI, Abbott JK, Gosden TP, Coreau A. 2009. Female polymorphisms, sexual conflict and limits to speciation processes in animals. Evol Ecol 23: 93-108.

Swanson WJ, Vacquier VD. 2002a. The rapid evolution of reproductive proteins. Nat Rev Genet 3: 137-144.

Swanson WJ, Vacquier VD. 2002b. Reproductive protein evolution. Annu Rev Ecol Syst 33: 161-179.

Swanson WJ, Aquadro CF, Vacquier VD. 2001. Polymorphism in abalone fertilization proteins is consistent with the neutral evolution of the egg's receptor for lysin (VERL) and positive Darwinian selection of sperm lysin. Mol Biol Evol 18: 376-383.

Swanson WJ, Nielsen R, Yang QF. 2003. Pervasive adaptive evolution in mammalian fertilization proteins. Mol Biol Evol 20: 18-20.

Tomaiuolo M, Levitan D. 2006. Modeling how reproductive ecology can drive protein diversification and result in linkage disequilibrium between sperm and egg proteins. Am Nat 176: 14-25.

Trivers RL. 1972. Parental investment and sexual selection. In Sexual selection and the descent of man 1871-1971 (ed. Campbell B), pp. 136-179. Aldine, Chicago.

Vacquier VD, Lee YH. 1993. Abalone sperm lysin: Unusual mode of evolution of a gamete recognition protein. $Z y$ gote 1: 181-196.

Vacquier VD, Moy GW. 1997. The fucose sulfate polymer of egg jelly binds to sperm REJ and is the inducer of the sea urchin sperm acrosome reaction. Dev Biol 192: 125-135.

Vacquier VD, Swanson WJ. 2011. Selection in the rapid evolution of gamete recognition proteins in marine invertebrates. Cold Spring Harb Perspect Biol 3: a002931.

van Doorn GS. 2009. Intralocus sexual conflict. Ann NY Acad Sci 1168: 52-71.

van Doorn GS, Edelaar P, Weissing FJ. 2009. On the origin of species by natural and sexual selection. Science 326: 1704-1707.

Van Gossum H, Sherratt TN, Cordero-Rivera A. 2008. The evolution of sex-limited colour polymorphism. In Dragonflies and damselflies: Model organisms for ecological and evolutionary research (ed. Cordoba-Aguilar A), pp. 219229. Oxford University Press, Oxford.

Wade MJ, Patterson H, Chang NW, Johnson NA. 1994. Postcopulatory, prezygotic isolation in flour beetles. Heredity 72: $163-167$.

Wigby S, Chapman T. 2006. No evidence that experimental manipulation of sexual conflict drives premating reproductive isolation in Drosophila melanogaster. J Evol Biol 19: $1033-1039$.

Yang ZH, Swanson WJ, Vacquier VD. 2000. Maximum-likelihood analysis of molecular adaptation in abalone sperm lysin reveals variable selective pressures among lineages and sites. Mol Biol Evol 17: 1446-1455. 


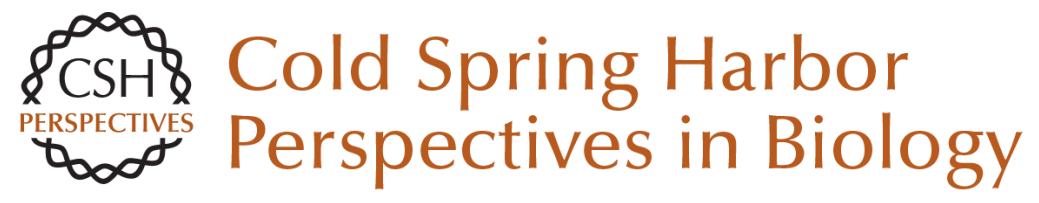

\section{Is Sexual Conflict an "Engine of Speciation"?}

Sergey Gavrilets

Cold Spring Harb Perspect Biol 2014; doi: 10.1101/cshperspect.a017723 originally published online November 13, 2014

\section{Subject Collection The Genetics and Biology of Sexual Conflict}

Mechanisms and Evidence of Genital Coevolution: The Roles of Natural Selection, Mate Choice, and Sexual Conflict

Patricia L.R. Brennan and Richard O. Prum

The Evolution of Sexually Antagonistic Phenotypes

Jennifer C. Perry and Locke Rowe

Reproductive Parasitism: Maternally Inherited

Symbionts in a Biparental World

Gregory D.D. Hurst and Crystal L. Frost

Sex-Biased Gene Expression and Sexual Conflict throughout Development

Fiona C. Ingleby, Ilona Flis and Edward H. Morrow

Human Homosexuality: A Paradigmatic Arena for

Sexually Antagonistic Selection?

Andrea Camperio Ciani, Umberto Battaglia and Giovanni Zanzotto

Sexual Conflict Arising from Extrapair Matings in Birds

Alexis S. Chaine, Robert Montgomerie and Bruce E. Lyon

Sexual Conflict and Seminal Fluid Proteins: A

Dynamic Landscape of Sexual Interactions

Laura K. Sirot, Alex Wong, Tracey Chapman, et al.

Conflict on the Sex Chromosomes: Cause, Effect, and Complexity

Judith E. Mank, David J. Hosken and Nina Wedell
Infanticide as Sexual Conflict: Coevolution of

Male Strategies and Female Counterstrategies Ryne A. Palombit

Copulatory Wounding and Traumatic Insemination

Klaus Reinhardt, Nils Anthes and Rolanda Lange

Sexual Conflict in Hermaphrodites

Lukas Schärer, Tim Janicke and Steven A. Ramm

Sexual Conflict and Sperm Competition

Dominic A. Edward, Paula Stockley and David J. Hosken

Sexually Antagonistic Zygotic Drive: A New Form of Genetic Conflict between the Sex

Chromosomes Urban Friberg and William R. Rice

Sex Chromosome Drive

Quentin Helleu, Pierre R. Gérard and Catherine Montchamp-Moreau

Is Sexual Conflict an "Engine of Speciation"? Sergey Gavrilets

Sexual Cannibalism as a Manifestation of Sexual Conflict

Jutta M. Schneider

For additional articles in this collection, see http://cshperspectives.cshlp.org/cgi/collection/

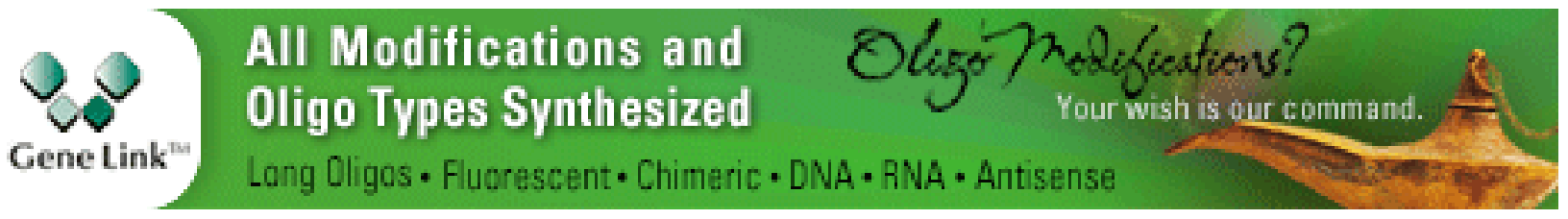


For additional articles in this collection, see http://cshperspectives.cshlp.org/cgi/collection/

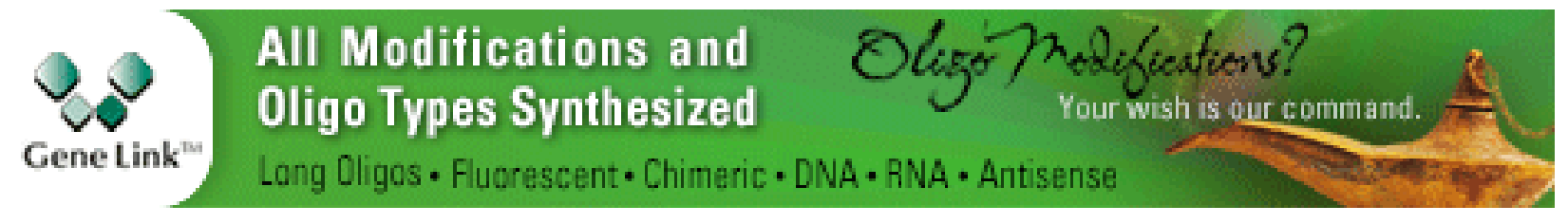

Copyright @ 2014 Cold Spring Harbor Laboratory Press; all rights reserved 